\title{
Fuel metabolism during exercise in euglycaemia and hyperglycaemia in patients with type 1 diabetes mellitus - a prospective single-blinded randomised crossover trial
}

\author{
S. Jenni • C. Oetliker $\cdot$ S. Allemann $\cdot$ M. Ith $\cdot$ L. Tappy $•$ \\ S. Wuerth • A. Egger • C. Boesch • Ph. Schneiter • \\ P. Diem • E. Christ • C. Stettler
}

Received: 27 February 2008 / Accepted: 18 April 2008/Published online: 30 May 2008

(C) Springer-Verlag 2008

\begin{abstract}
Aims/hypothesis We assessed systemic and local muscle fuel metabolism during aerobic exercise in patients with type 1 diabetes at euglycaemia and hyperglycaemia with identical insulin levels.

Methods This was a single-blinded randomised crossover study at a university diabetes unit in Switzerland. We studied seven physically active men with type 1 diabetes (mean \pm SEM age $33.5 \pm 2.4$ years, diabetes duration $20.1 \pm 3.6$ years, $\mathrm{HbA}_{1 \mathrm{c}}$
\end{abstract}

S. Jenni $\cdot$ C. Oetliker $\cdot$ S. Allemann $\cdot$ A. Egger $\cdot$ P. Diem $\cdot$

E. Christ $\cdot$ C. Stettler $(\bowtie)$

Division of Endocrinology, Diabetes and Clinical Nutrition, Inselspital, Bern University Hospital and University of Bern,

Freiburgstrasse CH-3010 Bern, Switzerland

e-mail: christoph.stettler@insel.ch

C. Oetliker

Department of Anaesthesia, University Hospital Basel,

Basel, Switzerland

S. Allemann $\cdot$ C. Stettler

Institute of Social and Preventive Medicine,

University of Bern, Bern, Switzerland

M. Ith $\cdot$ C. Boesch

Department for Clinical Research,

Magnetic Resonance Spectroscopy and Methodology,

University of Bern,

Bern, Switzerland

L. Tappy $\cdot$ P. Schneiter

Department of Physiology, University of Lausanne,

Lausanne, Switzerland

S. Wuerth

Institute for Sport Science, University of Basel,

Basel, Switzerland
$6.7 \pm 0.2 \%$ and peak oxygen uptake $\left[\dot{V} \mathrm{O}_{2 \text { peak }}\right] 50.3 \pm 4.5 \mathrm{ml}$ $\min ^{-1} \mathrm{~kg}^{-1}$ ). Men were studied twice while cycling for $120 \mathrm{~min}$ at 55 to $60 \%$ of $\dot{V} \mathrm{O}_{2 \text { peak }}$, with a blood glucose level randomly set either at 5 or $11 \mathrm{mmol} / 1$ and identical insulinaemia. The participants were blinded to the glycaemic level; allocation concealment was by opaque, sealed envelopes. Magnetic resonance spectroscopy was used to quantify intramyocellular glycogen and lipids before and after exercise. Indirect calorimetry and measurement of stable isotopes and counter-regulatory hormones complemented the assessment of local and systemic fuel metabolism.

Results The contribution of lipid oxidation to overall energy metabolism was higher in euglycaemia than in hyperglycaemia (49.4 \pm 4.8 vs $30.6 \pm 4.2 \% ; p<0.05$ ). Carbohydrate oxidation accounted for $48.2 \pm 4.7$ and $66.6 \pm 4.2 \%$ of total energy expenditure in euglycaemia and hyperglycaemia, respectively $(p<0.05)$. The level of intramyocellular glycogen before exercise was higher in hyperglycaemia than in euglycaemia $(3.4 \pm 0.3$ vs $2.7 \pm 0.2$ arbitrary units $[\mathrm{AU}] ; p<0.05)$. Absolute glycogen consumption tended to be higher in hyperglycaemia than in euglycaemia ( $1.3 \pm 0.3$ vs $0.9 \pm 0.1 \mathrm{AU})$. Cortisol and growth hormone increased more strongly in euglycaemia than in hyperglycaemia (levels at the end of exercise $634 \pm 52 \mathrm{vs}$ $501 \pm 32 \mathrm{nmol} / 1$ and $15.5 \pm 4.5 \mathrm{vs} 7.4 \pm 2.0 \mathrm{ng} / \mathrm{ml}$, respectively; $p<0.05$ ).

Conclusions/interpretation Substrate oxidation in type 1 diabetic patients performing aerobic exercise in euglycaemia is similar to that in healthy individuals revealing a shift towards lipid oxidation during exercise. In hyperglycaemia fuel metabolism in these patients is dominated by carbohydrate oxidation. Intramyocellular glycogen was not spared in hyperglycaemia.

Trial registration: ClinicalTrials.Gov NCT00325559 
Funding: This study was supported by unrestricted grants from the Oetliker-Stiftung für Physiologie, from the Swiss Diabetes Foundation, from NovoNordisk, Switzerland, and from the Swiss National Science Foundation.

Keywords Carbohydrate oxidation · Euglycaemia . Exercise · Glucose clamp · Glucose turnover . Hyperglycaemia $\cdot$ Insulin $\cdot$ Magnetic resonance spectroscopy $\cdot$ Type 1 diabetes mellitus

$\begin{array}{ll}\text { Abbreviations } \\ \mathrm{AU} & \text { arbitrary unit } \\ \mathrm{IMCL} & \text { intramyocellular lipids } \\ \mathrm{MRS} & \text { magnetic resonance spectroscopy } \\ R_{\mathrm{a}} & \text { rate of appearance } \\ R_{\mathrm{d}} & \text { rate of disappearance } \\ \mathrm{RPE} & \text { rate of perceived exertion } \\ \dot{V} \mathrm{CO}_{2} & \text { carbon dioxide production } \\ \dot{V} \mathrm{O}_{2} & \text { oxygen uptake } \\ \dot{V} \mathrm{O}_{2 \text { peak }} & \text { peak oxygen uptake }\end{array}$

\section{Introduction}

The performance of physical exercise imposes high demands on patients with type 1 diabetes mellitus. Although recommended by treatment guidelines [1], exercise may increase the risk of hypoglycaemia [2-4] and bears the risk of deteriorating diabetes control due to complex interference with the regulation of glucose transport into working muscle [5].

Detailed insight into the metabolic processes during exercise in type 1 diabetic patients could refine treatment recommendations during physical activity. However, quantitative data on fuel metabolism in exercising type 1 diabetic patients are scarce up to now. In clinical practice, patients are advised to adapt insulin doses when planning to perform exercise [1,6]. The effects of differing levels of insulin on substrate metabolism in exercising type 1 diabetic patients have recently been reported [7]. Conversely, little is known on the complementary impact of differing levels of blood glucose on fuel metabolism and exercise performance in these patients. Recently, we found the contribution of carbohydrate and lipid oxidation to overall energy consumption to be similar in euglycaemia and hyperglycaemia during exercise up to $40 \mathrm{~min}$, but the study design did not allow a detailed quantification of substrate fluxes [8]. Even less is known on the effect of differing glycaemic levels on fuel metabolism during aerobic exercise of longer duration in patients with type 1 diabetes mellitus. Studies in healthy individuals have consistently shown that increased availability of carbohydrates before or during exercise increased carbohydrate oxidation [9-13].
However, it is uncertain whether increased carbohydrate availability also induces a saving of intramyocellular glycogen during exercise [9, 14-20]. Interestingly, in healthy individuals, hyperglycaemia is generally accompanied by physiological hyperinsulinaemia, thereby hampering direct application of these findings to diabetic patients.

The aim of the present study was to comprehensively compare the local and systemic fuel metabolism of type 1 diabetic patients performing aerobic exercise under stable euglycaemic and hyperglycaemic conditions at a similar and comparably low insulinaemia. We hypothesised that: (1) in euglycaemia, they would behave similarly to nondiabetic individuals, shifting fuel oxidation towards consumption of lipids in the course of exercise; (2) in hyperglycaemia, they would show persistent oxidation of carbohydrates; and (3) intramyocellular glycogen would be spared in hyperglycaemia, but not in euglycaemia.

\section{Methods}

Patients, preliminary peak oxygen uptake testing We recruited seven physically active male volunteers with type 1 diabetes mellitus for this study. Mean \pm SEM age and BMI were $33.5 \pm 2.4$ years and $24.3 \pm 0.4 \mathrm{~kg} / \mathrm{m}^{2}$. Average duration of physical exercise was $255 \pm 65 \mathrm{~min}$ per week. Diabetes duration was $20.1 \pm 3.6$ years, and all volunteers had continuous subcutaneous insulin infusion, with a mean insulin dose of $0.61 \pm 0.05 \mathrm{U} \mathrm{kg}^{-1} \mathrm{day}^{-1}$. $\mathrm{HbA}_{1 \mathrm{c}}$ was $6.7 \pm$ $0.2 \%$. Informed written consent was obtained and the study was approved by the local Ethics Committee. Peak oxygen uptake $\left(\dot{V} \mathrm{O}_{2 \text { peak }}\right)$ was determined during a stepwise incremental test on a bicycle ergometer with breath-to-breath spirometry (Cardiovit AT-104PC; Schiller, Baar, Switzerland). The criteria used for attainment of $\dot{V} \mathrm{O}_{2 \text { peak }}$ were as follows: a heart rate $>90 \%$ of predicted value, inability to pedal at a rate of $60 \mathrm{rev} / \mathrm{min}$, a near maximal rate of perceived exertion (RPE) $\geq 19$ [21] and a respiratory exchange ratio $>1.10$. Mean $\dot{V} \mathrm{O}_{2 \text { peak }}$ was $50.3 \pm 4.5 \mathrm{ml}$ $\min ^{-1} \mathrm{~kg}^{-1}$.

Study design This was a randomised, single-blinded, crossover trial. Each participant was investigated twice at an interval of 7 weeks (range 6-10). Patients were blinded to glycaemia, randomly set to either euglycaemia or hyperglycaemia. Randomisation was by sealed opaque envelopes. Prior to the first test, participants were familiarised with the study procedures including a full ride over $120 \mathrm{~min}$. The experimental plan of the main test is outlined in Fig. 1.

Pre-test standardisation procedures and overnight preparation phase Prior to the main test, patients followed an 


\begin{tabular}{|l|c|c|c|c|}
\hline $\begin{array}{c}\text { Overnight } \\
\text { euglycaemia }\end{array}$ & $\begin{array}{c}\text { Transfer } \\
\text { and start } \\
\text { clamp }\end{array}$ & MRS 1 & $\begin{array}{c}\text { Exercise } \\
120 \mathrm{~min}\end{array}$ & MRS 2 \\
\hline
\end{tabular}

Fig. 1 Experimental plan. Timepoint $0\left(t_{0}\right)$ denotes start of exercise. Dashed line, duration of euglycaemic or hyperglycaemic clamp procedure

isoenergetic diet (145-165 kJ/kg body weight; $60 \%$ carbohydrate, $20 \%$ protein, $20 \%$ fat). Strenuous exercise was not allowed for $72 \mathrm{~h}$ and the patients refrained from alcohol for $48 \mathrm{~h}$ before the main test. Patients arrived at the hospital the night before the main experiment and stayed overnight. At 20:00 hours they were offered a standardised meal corresponding to $35 \%$ of their expected basal energy requirements ( $60 \%$ carbohydrate, $20 \%$ fat and $20 \%$ protein). Continuous subcutaneous insulin infusion was disconnected at 21:00 and an indwelling $18 \mathrm{G}$ cannula was inserted into one vein of each forearm, for sampling and administration of insulin, glucose and tracer, respectively. Overnight, glucose concentrations were maintained within the $4-7 \mathrm{mmol} / \mathrm{l}$ range with variable infusion of regular insulin (Actrapid; Novo Industries, Copenhagen, Denmark). Patients were then kept fasting but had free access to sugar-free water until the end of the study on the following day.

Exercise test and spirometry The exercise consisted of $120 \min \left(\operatorname{start}=t_{0}\right)$ cycling at a power corresponding to 55$60 \% \dot{V} \mathrm{O}_{2 \text { peak }}$. Spirometry was performed from $t_{-10}$ to $t_{15}, t_{50}$ to $t_{70}$ and $t_{100}$ to $t_{120}$. Urinary urea and glucose concentrations were analysed before and during exercise to quantify nitrogen excretion [22] and glucose spill-over. Rates of substrate oxidation were then calculated using standard equations [23, 24]. ECG was monitored continuously, blood pressure was regularly measured and RPE was assessed by the Borg scale every $10 \mathrm{~min}$.

Euglycaemic and hyperglycaemic clamp procedures For the clamp the insulin infusion was fixed at a rate (median $7 \mathrm{mU} \mathrm{m}^{-2}$ $\min ^{-1}$, range $5-8.2 \mathrm{mU} \mathrm{m}^{-2} \mathrm{~min}^{-1}$ ) corresponding to the individual reduced basal rate commonly applied during a similar exercise. Euglycaemia (target level $5 \mathrm{mmol} / \mathrm{l}$ ) or hyperglycaemia (target level $11 \mathrm{mmol} / \mathrm{l}$ ) were maintained by infusion of $20 \%$ dextrose [25]. Blood glucose was measured every $5 \mathrm{~min}$ and glucose infusion was adapted accordingly. When stable glycaemia was reached, infusions of stable isotopic tracers were started: D-[U- $\left.{ }^{13} \mathrm{C}\right]$ glucose was infused at a rate of $1.25 \mu \mathrm{g} \mathrm{kg}^{-1} \mathrm{~min}^{-1}$ (primed with $25 \mu \mathrm{g} \mathrm{kg}^{-1}$ $\left.[\mathrm{mmol} / \mathrm{l} \text { glucose }]^{-1}\right)$. D- $\left[6-6-{ }^{2} \mathrm{H}_{2}\right]$ Glucose was infused at a rate of $30 \mu \mathrm{g} \mathrm{kg}^{-1} \mathrm{~min}^{-1}$ (primed with $0.6 \mathrm{mg} \mathrm{kg}^{-1}[\mathrm{mmol} /$ 1 glucose $]^{-1}$ ). The bicarbonate pool was simultaneously primed with $6 \mu \mathrm{mol} / \mathrm{kg} \mathrm{NaH}^{13} \mathrm{CO}_{3}$. During exercise the infusion rates were quadrupled in order to minimise changes in enrichment [26]. Isotopes were manufactured by Cambridge Isotope Laboratories, Innerberg, Switzerland. Sterile pathogen-free solutions were prepared by the University Hospital Pharmacy, Lausanne, Switzerland.

Samples and biochemical analysis Blood glucose and lactate were measured every $5 \mathrm{~min}$ by an immobilised glucose-oxidase and lactate-oxidase method (YSI2300; Yellow Springs Instruments, Yellow Springs, OH, USA) and are presented in 15 min intervals. Serum insulin and NEFA were sampled twice before exercise and every 15 min during exercise. NEFA were determined using a commercially available kit (Wako Pure Chemical, VWR International, Dietikon, Switzerland). Counter-regulatory hormones were sampled twice before exercise and twice during the last $10 \mathrm{~min}$ of the exercise. They are reported as mean pre- and post-test values. Catecholamine levels were determined by high-performance liquid chromatography (PU-980; Jasco, Tokyo, Japan) coupled to an electrochemical detector (CLC 100; Chromosystems, Munich, Germany). Growth hormone was measured using a chemiluminescence method (Immulite One; DPC, Los Angeles, CA, USA). Glucagon was measured using a double radioimmunoassay (Siemens Medical Solutions Diagnostic, Los Angeles, CA, USA) in EDTA plasma mixed with aprotinin, immediately cooled and frozen after separation. Cortisol and insulin were measured with electro-chemiluminescence immunoassays (Roche Modular-E170; Roche Diagnostics, Rotkreuz, Switzerland).

Tracer samples and glucose turnover Double background enrichment measurements (blood and breath samples) were taken prior to infusion at 07:00 hours $\left(t_{-180}\right)$. After a 160 min equilibration phase to reach steady-state tracer enrichments, two blood and breath samples were obtained before exercise $\left(t_{-20}\right.$ and $\left.t_{-10}\right)$. Blood samples were obtained during exercise at $t_{90}, t_{100}, t_{110}$ and $t_{120}$. Breath samples were obtained at $t_{90}$ and $t_{120}$ and collected in vitreous tubes. Isotopic enrichments of D- $\left[6-6-{ }^{2} \mathrm{H}_{2}\right]$ glucose were determined by gas-chromatography mass-spectrometry (GC 5890/MS 5971; Hewlett-Packard, Palo Alto, CA, USA). Isotopic enrichment of ${ }^{13} \mathrm{CO}_{2}$ and ${ }^{13} \mathrm{C}$ glucose was measured by isotope ratio mass spectrometry (Tracermass ${ }^{13} \mathrm{C} /{ }^{15} \mathrm{~N}$; Europa Scientific, Crewe, UK). At rest glucose rate of appearance $\left(R_{\mathrm{a}}\right)$ and rate of disappearance $\left(R_{\mathrm{d}}\right)$ were calculated from D-[6-6- $\left.{ }^{2} \mathrm{H}_{2}\right]$ glucose enrichments using Steele's equations [26]. During exercise non-steady state conditions were presumed and $R_{\mathrm{a}}$ and $R_{\mathrm{d}}$ were calculated using the modified Steele equations for non-steady state conditions [26] assuming an effective fraction of 0.65 and a distribution volume of $0.22 \mathrm{l} / \mathrm{kg}$. The oxidation rate of 
systemic glucose was calculated from labelled ${ }^{13} \mathrm{CO}_{2}$ and labelled $\mathrm{D}-\left[\mathrm{U}_{-}{ }^{13} \mathrm{C}\right]$ glucose, using a recovery factor of 0.8 during rest and 1.0 during the exercise [27]. Endogenous glucose production was calculated from the infusion rate and the total $R_{\mathrm{a}}$. Glucose disposal was calculated by taking into account the urinary glucose loss. The difference between net carbohydrate oxidation and the oxidation of systemic glucose was used to calculate glycogen breakdown rates.

Magnetic resonance spectroscopy Muscular glycogen [28] and intramyocellular lipids (IMCL) [29] were measured sequentially in the right $\mathrm{m}$. quadriceps by ${ }^{13} \mathrm{C}$ and ${ }^{1} \mathrm{H}$ magnetic resonance spectroscopy (MRS) before and after exercise on both test occasions (total four measurements per participant). Mean \pm SEM interval between start of the clamp and start of the MRS was $55 \pm 7 \mathrm{~min}$. The right leg was placed in a specially designed cast to guarantee a reproducible position of the muscle within the magnetic field. Positioning at initial measurement and repositioning (the following three measurements) of the ${ }^{1} \mathrm{H} /{ }^{13} \mathrm{C}$-coil as well as of the ${ }^{1} \mathrm{H}$-voxel was monitored by two series of localiser images. The total time for one combined measurement of glycogen and IMCL was $95 \mathrm{~min}$. All MRS examinations were performed on a clinical $1.5 \mathrm{~T}$ wholebody scanner (SIGNA, General Electric, Milwaukee, WI, USA) equipped with a ${ }^{13} \mathrm{C} /{ }^{1} \mathrm{H}$ double-tuned flexible coil $\left({ }^{1} \mathrm{H}\right.$ : Helmholtz design, ${ }^{13} \mathrm{C}$ : single turn $11.5 \times 11.5 \mathrm{~cm}^{2}$, Medical Advance, Milwaukee, WI, USA).

For ${ }^{1} \mathrm{H}$-MRS, IMCL was measured in an $11 \times 12 \times 18 \mathrm{~mm}^{3}$ (in right/left $\times$ anterior/posterior $\times$ inferior/superior directions) sized voxel in $\mathrm{m}$. vastus intermedius using an optimised short echo time point resolved spectroscopy (PRESS) sequence (repetition time $\mathrm{TR}=3 \mathrm{~s}$, echo time $\mathrm{TE}=20 \mathrm{~ms}$, $2,000 \mathrm{~Hz}, 1,024$ pts, 128 acquisitions, water presaturation and outer volume suppression) and quantified using the unsuppressed fully relaxed water signal as internal concentration standard. IMCL concentrations in absolute units of mmol per $\mathrm{kg}$ muscle wet weight $\left(\mathrm{mmol} / \mathrm{kg}_{\mathrm{ww}}\right)$ were calculated as reported earlier [30]. A reproducibility study revealed a typical $\mathrm{CV}$ of $6 \%$ for repeated measurements [29] of IMCL.

For ${ }^{13} \mathrm{C}$-MRS, glycogen and creatine content were measured by ${ }^{13} \mathrm{C}$-MRS using a pulse-and-acquire sequence (adiabatic $90^{\circ}$ excitation, repetition time $\mathrm{TR}=165 \mathrm{~ms}$, $5,000 \mathrm{~Hz}, 512$ pts, 12,000 acquisitions per measurement). ${ }^{1} \mathrm{H}$ decoupling during data acquisition and nuclear Overhauser effect build-up between the acquisitions were done using a partially home-built second channel. Absolute glycogen concentrations were normalised to the creatine signal and expressed in arbitrary units (AU). Relative glycogen changes denote percentage changes during exercise. Signals of glycogen and creatine were evaluated using the jMRUI software package (version 3.0, Magnetic Resonance User Interface, University of Barcelona, Spain) as described in detail in [31].

Statistical analysis Values are expressed as mean \pm SEM. Non-normally distributed data were log-transformed. Paired data were compared using Student's $t$ test. For parameters with repeated measurements, AUCs were calculated. All analyses were performed using Stata version 9.2 (Stata Corporation, College Station, TX, USA).

\section{Results}

Euglycaemic and hyperglycaemic clamp procedures Insulin levels did not differ between euglycaemia and hyperglycaemia, with mean levels during exercise at $121.5 \pm$ 21.5 and $123.6 \pm 22.2 \mathrm{pmol} / \mathrm{l}$ respectively (Fig. 2a). Mean blood glucose during exercise was $5.4 \pm 0.5 \mathrm{mmol} / 1$ for euglycaemia and $11.0 \pm 0.3 \mathrm{mmol} / \mathrm{l}$ for hyperglycaemia ( $p<$ 0.001) (Fig. 2b). The total amount of infused glucose was higher for hyperglycaemia than for euglycaemia $(733 \pm 182$ and $283 \pm 89 \mathrm{mg} / \mathrm{kg} ; p<0.05$ ).

Exercise levels Mean exercise levels were similar in euglycaemia and hyperglycaemia $(57.0 \pm 1.4$ and $56.6 \pm$
Fig. 2 Insulin (a) and glucose (b) concentrations during rest and during $120 \mathrm{~min}$ of exercise in euglycaemia (black circles) and hyperglycaemia (white squares). Data are mean \pm SEM $(n=7) .{ }^{*} p<0.05$ for differences between trials
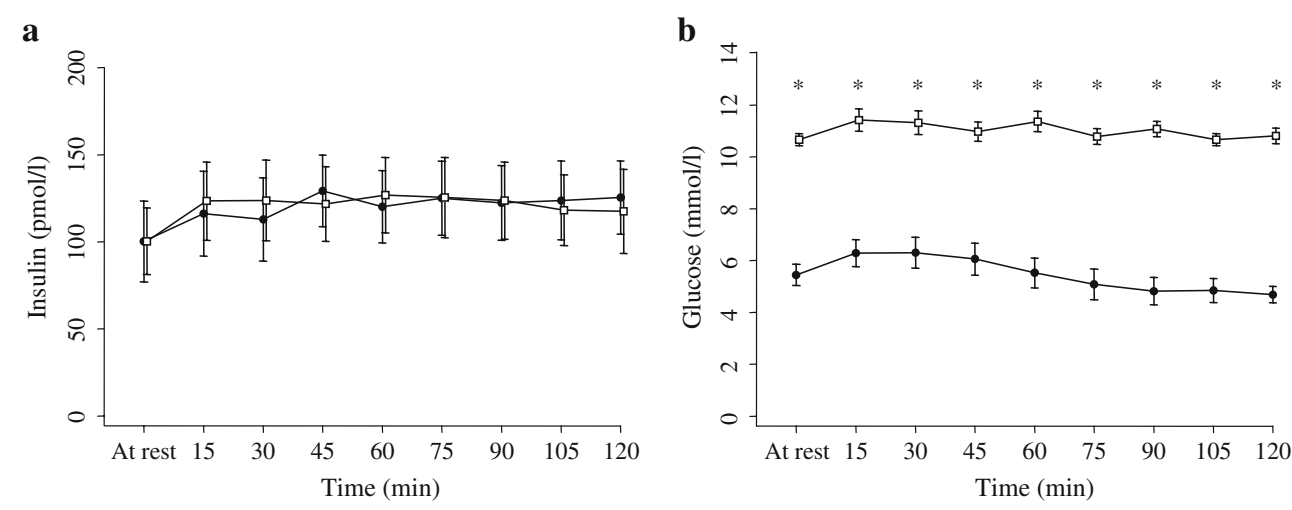
$1.2 \%$ of predetermined $\dot{V} \mathrm{O}_{2 \text { peak }}$, respectively). There was an identical increase in RPE from baseline throughout the exercise in euglycaemia and in hyperglycaemic exercise conditions. Values at the end of exercise were $16.1 \pm 0.8$ in euglycaemia and $15.6 \pm 0.9$ in hyperglycaemia. Lactate levels were similar in euglycaemia and hyperglycaemia, starting at $0.6 \pm 0.1$ and $0.7 \pm 0.1 \mathrm{mmol} / \mathrm{l}$ at baseline and increasing to a maximum of $1.3 \pm 0.3$ and $1.4 \pm 0.3 \mathrm{mmol} /$ 1 respectively after $30 \mathrm{~min}$. Thereafter, lactate levels declined in both groups, levels being lower in euglycaemia than in hyperglycaemia during the second hour of exercise $(p<0.05$ for AUC $)$.

Spirometry and net carbohydrate and lipid oxidation rates Table 1 sums up the respiratory gas exchange at rest and during exercise. There were no baseline differences in $\dot{V} \mathrm{O}_{2}$ and $\mathrm{CO}_{2}$ production $\left(\dot{V} \mathrm{CO}_{2}\right)$ between euglycaemia and hyperglycaemia. The increase of $\dot{V} \mathrm{O}_{2}$ during exercise was more pronounced in euglycaemia than in hyperglycaemia, resulting in a higher level of $\dot{V} \mathrm{O}_{2}$ at the end of exercise in the former condition $\left(29.7 \pm 2.1 \mathrm{vs} 28.4 \pm 2.0 \mathrm{ml} \mathrm{min}^{-1} \mathrm{~kg}^{-1}\right.$, $p<0.05$ ). Values for $\dot{V} \mathrm{CO}_{2}$ were similar in euglycaemia and hyperglycaemia throughout the entire exercise. This translated into a higher respiratory exchange ratio during exercise in hyperglycaemia than in euglycaemia $(0.89 \pm 0.01$ vs $0.84 \pm$ 0.01 at the end of exercise; $p<0.05$ ). The contribution of net carbohydrate oxidation to overall substrate oxidation was higher in hyperglycaemia than in euglycaemia $(66.6 \pm 4.2 \mathrm{vs}$ $48.2 \pm 4.7 \%$ at the end of exercise; $p<0.05$ ). Inverse findings resulted for the contribution of net lipid oxidation to overall

Table 1 Respiratory gas exchange and net substrate oxidation rates

\begin{tabular}{|c|c|c|c|}
\hline \multirow[t]{2}{*}{ Parameter } & \multirow[t]{2}{*}{ Rest } & \multicolumn{2}{|l|}{ Exercise } \\
\hline & & $60 \mathrm{~min}$ & $120 \mathrm{~min}$ \\
\hline \multicolumn{4}{|c|}{$\dot{V} \mathrm{O}_{2}\left(\mathrm{ml} \mathrm{min}^{-1} \mathrm{~kg}^{-1}\right)$} \\
\hline Euglycaemia & $4.4 \pm 0.8$ & $28.6 \pm 2.4^{\mathrm{c}}$ & $29.7 \pm 2.1^{\mathrm{c}, \mathrm{d}}$ \\
\hline \multicolumn{4}{|c|}{$\dot{V} \mathrm{CO}_{2}\left(\mathrm{ml} \mathrm{min}{ }^{-1} \mathrm{~kg}^{-1}\right)$} \\
\hline Euglycaemia & $3.4 \pm 0.6$ & $24.5 \pm 2.0^{\mathrm{c}}$ & $24.9 \pm 1.9^{\mathrm{c}}$ \\
\hline Hyperglycaemia & $3.9 \pm 0.2$ & $25.0 \pm 1.7^{\mathrm{c}}$ & $25.4 \pm 1.8^{\mathrm{c}}$ \\
\hline \multicolumn{4}{|c|}{ Carbohydrate oxidation $\left(\mathrm{mg} \mathrm{min}^{-1} \mathrm{~kg}^{-1}\right)$} \\
\hline Euglycaemia & $1.2 \pm 0.4$ & $19.1 \pm 2.0^{\mathrm{c}}$ & $17.5 \pm 2.5^{\mathrm{c}}$ \\
\hline Hyperglycaemia & $1.0 \pm 0.4$ & $22.6 \pm 2.1^{\mathrm{c}}$ & $23.7 \pm 2.1^{\mathrm{a}, \mathrm{c}}$ \\
\hline \multicolumn{4}{|c|}{ Lipid oxidation (mg $\min ^{-1} \mathrm{~kg}^{-1}$ ) } \\
\hline Euglycaemia & $1.6 \pm 0.4$ & $6.6 \pm 0.8^{\mathrm{c}}$ & $7.7 \pm 0.8^{\mathrm{c}, \mathrm{c}}$ \\
\hline Hyperglycaemia & $1.7 \pm 0.2$ & $5.1 \pm 0.9^{\mathrm{b}}$ & $4.8 \pm 0.8^{\mathrm{a},}$ \\
\hline
\end{tabular}

Data are mean $\pm \operatorname{SEM}(n=7)$

Data are reported as mean over $5 \mathrm{~min}$ at rest and mean over each $15 \mathrm{~min}$ from $t_{55}$ to $t_{70}$ and from $t_{105}$ to $t_{120}$

${ }^{\mathrm{a}} p<0.05$ for hyperglycaemia compared with euglycaemia; ${ }^{\mathrm{b}} p<0.01$ compared with the corresponding baseline value; ${ }^{\mathrm{c}} p<0.001$ compared with the corresponding baseline value; ${ }^{\mathrm{d}} p<0.05$ compared with the corresponding value at $60 \mathrm{~min}$
Table 2 Glucose turnover

\begin{tabular}{lcc}
\hline Parameter & \multicolumn{1}{c}{ Rest } & Exercise \\
\hline Endogenous glucose production $\left(\mathrm{mg} \mathrm{min}^{-1} \mathrm{~kg}^{-1}\right)$ & \\
Euglycaemia & $2.4 \pm 0.2$ & $4.0 \pm 0.6^{\mathrm{c}}$ \\
Hyperglycaemia & $1.9 \pm 0.6$ & $1.9 \pm 0.8^{\mathrm{b}}$ \\
Glucose disposal $\left(\mathrm{mg} \mathrm{min}^{-1} \mathrm{~kg}^{-1}\right)$ & \\
Euglycaemia & $2.6 \pm 0.1$ & $8.4 \pm 0.8^{\mathrm{e}}$ \\
Hyperglycaemia & $2.9 \pm 0.3$ & $11.3 \pm 1.6^{\mathrm{d}}$ \\
Oxidation rate of systemic glucose $\left(\mathrm{mg} \mathrm{min}^{-1} \mathrm{~kg}^{-1}\right)$ & \\
Euglycaemia & $1.9 \pm 0.3$ & $8.4 \pm 1.1$ \\
Hyperglycaemia & $1.6 \pm 0.1$ & $10.3 \pm 1.3^{\mathrm{e}}$ \\
Glycogen breakdown rate $\left(\mathrm{mg} \mathrm{min}^{-1} \mathrm{~kg}^{-1}\right)$ & \\
Euglycaemia & $-0.8 \pm 0.6$ & $9.3 \pm 2.4^{\mathrm{d}}$ \\
Hyperglycaemia & $-0.6 \pm 0.4$ & $13.2 \pm 1.8^{\mathrm{a}, \mathrm{e}}$ \\
\hline
\end{tabular}

Data are mean $\pm \operatorname{SEM}(n=7)$; data at rest are mean of two measurements and during exercise mean of four measurements during the last $30 \mathrm{~min}$ Rate of appearance and disappearance were derived from D- $\left[6-6-{ }^{2} \mathrm{H}_{2}\right]$ glucose enrichment and oxidation rate of systemic glucose from ${ }^{13} \mathrm{CO}_{2}$ and $\mathrm{D}-\left[\mathrm{U}_{-}{ }^{13} \mathrm{C}\right]$ glucose

${ }^{\mathrm{a}} p<0.05$ for hyperglycaemia compared with euglycaemia; ${ }^{\mathrm{b}} p<0.01$ for hyperglycaemia compared with euglycaemia; ${ }^{\mathrm{c}} p<0.05$ compared with the corresponding baseline values; ${ }^{\mathrm{d}} p<0.01$ compared with the corresponding baseline values; ${ }^{\mathrm{e}} p<0.001$ compared with the corresponding baseline values

substrate oxidation, which was higher in euglycaemia than in hyperglycaemia $(49.4 \pm 4.8$ vs $30.6 \pm 4.2 \%$; $p<0.05)$.

Local and systemic carbohydrate metabolism During the first $30 \mathrm{~min}$ of exercise, glucose infusion rates were low in euglycaemia and hyperglycaemia $(0.3 \pm 0.2$ and $1.8 \pm 1.0 \mathrm{mg}$ $\mathrm{min}^{-1} \mathrm{~kg}^{-1}$ ). Rates increased throughout exercise to $4.4 \pm 1.2$ and $9.5 \pm 1.5 \mathrm{mg} \mathrm{min}{ }^{-1} \mathrm{~kg}^{-1}$ during the last $30 \mathrm{~min}$ in euglycaemia and hyperglycaemia $(p<0.01)$. Table 2 shows the parameters of glucose turnover assessed by stable isotope technique. Endogenous glucose production was at similarly low levels at rest in euglycaemia and hyperglycaemia $(2.4 \pm$ 0.2 and $1.9 \pm 0.6 \mathrm{mg} \mathrm{min}^{-1} \mathrm{~kg}^{-1}$ ). In euglycaemia endogenous glucose production significantly increased during exercise (to $4.0 \pm 0.6 \mathrm{mg} \mathrm{min}^{-1} \mathrm{~kg}^{-1}$ during the last $30 \mathrm{~min}$; $p<0.05$ compared with rest), but remained stable in hyperglycaemia $(1.9 \pm 0.8 ; p<0.01$ for difference to euglycaemia). Conversely, glucose disposal tended to be higher during exercise in hyperglycaemia than in euglycaemia $(11.3 \pm 1.6$ vs $8.4 \pm 0.8 \mathrm{mg} \mathrm{min}^{-1} \mathrm{~kg}^{-1}$ for last $30 \mathrm{~min}$ ). The oxidation rate of systemic glucose corresponded well to the glucose disposal and tended to be higher in hyperglycaemia than in euglycaemia towards the end of exercise $(10.3 \pm 1.3$ vs $8.4 \pm$ $1.1 \mathrm{mg} \mathrm{min}{ }^{-1} \mathrm{~kg}^{-1}$ ).

The calculated glycogen breakdown rates at the end of exercise were lower in euglycaemia than in hyperglycaemia $\left(9.3 \pm 2.4\right.$ and $\left.13.2 \pm 1.8 \mathrm{mg} \mathrm{min}{ }^{-1} \mathrm{~kg}^{-1} ; p<0.05\right)$. The corresponding results from MRS are shown in Fig. 3a, where absolute levels of glycogen before exercise are seen to be 
Fig. 3 Results from MRS for glycogen:creatine ratio (a) and IMCL (b) concentrations in the right thigh (in absolute units of mmol per kg muscle wet weight $\left[\mathrm{mmol} / \mathrm{kg}_{\mathrm{ww}}\right]$ ) before and after exercise in euglycaemia and hyperglycaemia. Data are mean \pm SEM $(n=7)$. ${ }^{*} p=0.05 ; * * * p<0.001$ ${ }^{\dagger} p=0.04 ;{ }^{\ddagger} p=0.003$ a

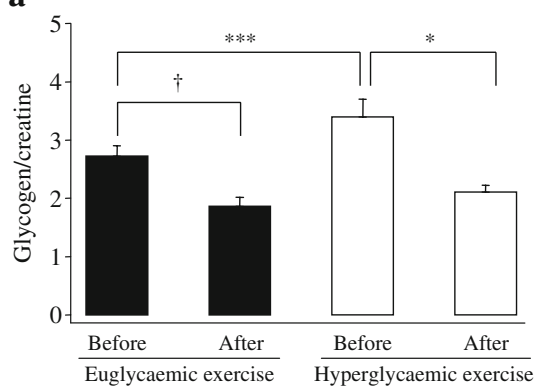

b

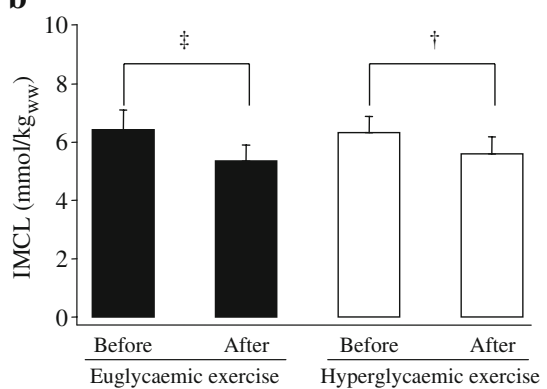

higher in hyperglycaemia than in euglycaemia $(3.4 \pm 0.3 \mathrm{vs}$ $2.7 \pm 0.2 \mathrm{AU} ; p<0.05)$. Absolute glycogen consumption tended to be higher in hyperglycaemia than in euglycaemia $(1.3 \pm 0.3$ vs $0.9 \pm 0.1 \mathrm{AU})$ while relative proportions were comparable for both glycaemic levels (35.2 \pm 6.5 and $31.2 \pm$ $3.5 \%)$.

Local and systemic lipid metabolism As shown in Table 1, the increase of the net lipid oxidation rate was more pronounced in euglycaemia than in hyperglycaemia $(7.7 \pm$ $0.8 \mathrm{vs} 4.8 \pm 0.8 \mathrm{mg} \mathrm{min}^{-1} \mathrm{~kg}^{-1}$ at the end of exercise; $p<$ $0.05)$. Levels of NEFA during exercise tended to be higher in euglycaemia than in hyperglycaemia $(0.63 \pm 0.07$ vs $0.56 \pm$ $0.05 \mathrm{mmol} / \mathrm{l})$. Baseline levels of IMCL assessed by MRS were comparable in both conditions (euglycaemia $6.4 \pm 0.7$ vs $6.3 \pm 0.6 \mathrm{mmol} / \mathrm{kg}$ muscle wet weight; Fig. 3b). The relative and absolute amounts of IMCL consumed during exercise tended to be higher in euglycaemic than in hyperglycaemic conditions $(-1.1 \pm 0.2$ and $-0.7 \pm 0.4 \mathrm{mmol} / \mathrm{kg}$ muscle wet weight and $-16.2 \pm 2.6$ and $-11.5 \pm 4.9 \%)$.

Summary of energy consumption Figure 4 summarises the relative contribution of local and systemic fuel sources to overall energy metabolism. In euglycaemia, $49.4 \pm 4.8 \%$ of the total energy demands was met by lipid oxidation, while carbohydrate oxidation accounted for $48.2 \pm 4.7 \%$. About half of carbohydrate oxidation $(24.2 \pm 6.0 \%)$ was from oxidised intramyocellular glycogen, the other half was accounted for by systemic glucose $(11.9 \pm 2.2 \%$ by endogenous hepatic glucose production, $12.2 \pm 3.4 \%$ by exogenous glucose infusion). In hyperglycaemia, the contribution of lipid oxidation to overall energy consumption was lower than in euglycaemia $(30.6 \pm$ $4.2 \% ; p<0.05)$. Conversely, significantly more energy was provided by carbohydrate oxidation in hyperglycaemia than in euglycaemia $(66.6 \pm 4.2 \% ; p<0.05)$. In hyperglycaemia, oxidation from systemically available glucose was mainly fed by exogenous glucose infusion (25.6 $\pm 5.1 \%$ ), while endogenous hepatic glucose production was significantly lower than in euglycaemia $(4.2 \pm 1.7 \% ; p<0.01)$. Protein oxidation was similarly low in both conditions (euglycaemia $2.4 \pm 0.2$ vs $2.8 \pm 0.3 \%)$.
Hormonal regulation Figure 5 depicts the levels of counterregulatory hormones before and at the end of exercise. While levels for cortisol (Fig. 5a) were not different at baseline in either condition (euglycaemia $449 \pm 55$ vs $501 \pm$ $73 \mathrm{nmol} / \mathrm{l}$ ), there was a significant increase during euglycaemia but not in hyperglycaemia (levels at the end of exercise $634 \pm 52$ vs $501 \pm 32 \mathrm{nmol} / 1 ; p<0.05)$. Similarly, levels of growth hormone (Fig. 5b) were comparable before exercise in both conditions (euglycaemia $2.6 \pm 1.2$ vs $3.3 \pm$ $2.1 \mu \mathrm{g} / \mathrm{l})$. During exercise there was a stronger increase in growth hormone in euglycaemic than in hyperglycaemic exercise conditions, resulting in significantly higher levels at the end of exercise in the former (euglycaemia 15.5 \pm 4.5 vs $7.4 \pm 2.0 \mu \mathrm{g} / \mathrm{l} ; p<0.05)$. Levels of norepinephrine and

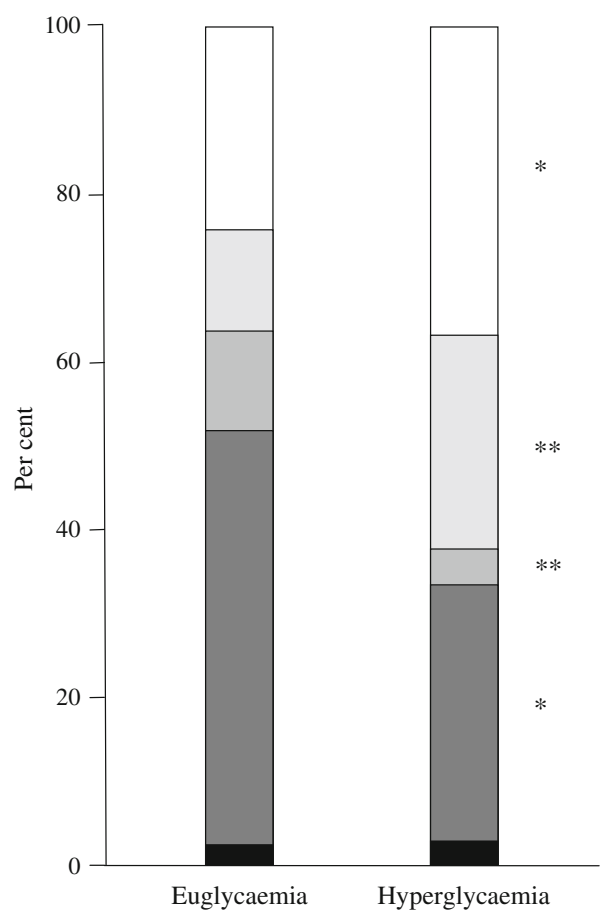

Fig. 4 Relative energy contribution of specific substrates at the end of exercise during euglycaemia and hyperglycaemia. Data are means $(n=$ $7) ; * p<0.05$ and $* * p<0.01$ for comparison of corresponding energy substrates in euglycaemia and hyperglycaemia. White, glycogen; light grey, glucose infusion; medium grey, endogenous glucose; dark grey, lipids; black, protein 
epinephrine (Fig. 5c,d) were similar at baseline and increased moderately and to a similar extent in euglycaemia and hyperglycaemia. Similarly, levels of glucagon (Fig. 5e) were not different between the two conditions either before or at the end of exercise.

\section{Discussion}

This is the first study to assess the impact of differing glucose levels at similar and comparably low insulinaemia on fuel metabolism during aerobic exercise in patients with type 1 diabetes mellitus. The principal findings were that: (1) during exercise the rate of carbohydrate oxidation was higher in hyperglycaemia than in euglycaemia; conversely, the rate of lipid oxidation was higher in the latter; (2) intramyocellular glycogen was not spared in hyperglycaemia and glycogen breakdown was even increased in this condition compared with euglycaemia; and (3) in the presence of identical insulin concentrations hyperglycaemia rapidly increased pre-exercise intramuscular glycogen.

This confirms our hypothesis of a shift from carbohydrate oxidation towards a predominance of lipid oxidation in the course of aerobic exercise in euglycaemia but not in hyperglycaemia, if insulin infusion is adapted in patients with type 1 diabetes mellitus. The relative contributions of carbohydrate and lipid oxidation to overall energy production found in the present study in euglycaemia were virtually identical to those reported in the study of Hawley and colleagues in healthy athletes exercising in euglycaemia and hyperglycaemia [12]. In the present study the relative contributions in euglycaemia were $49 \%, 24 \%$ and $24 \%$ for lipids, systemic glucose and local glycogen, while their values in euglycaemia were $53 \%, 26 \%$ and $21 \%$. It can, consequently, be stated that patients with type 1 diabetes mellitus performing aerobic exercise in euglycaemia behave metabolically in a similar way to healthy individuals.

The underlying mechanisms for these findings are not entirely known. During moderate exercise $(<60 \%$ of $\dot{V} \mathrm{O}_{2 \text { peak }}$ ) the ratio of glucagon to insulin is the main regulator of fuel metabolism in healthy individuals [32]. In the present study both insulin and glucagon were not different in euglycaemia and hyperglycaemia and are, therefore, unlikely to have caused the shift in fuel oxidation. Similarly, the levels of catecholamines were virtually identical in both glycaemia conditions. In contrast, differences were observed for cortisol and growth hormone. Thus while baseline levels of cortisol were identical in euglycaemia and hyperglycaemia, they increased during exercise in euglycaemia, but not in hyperglycaemia. Comparably, the levels of growth hormone, also similar at baseline, increased to a greater extent during euglycaemia compared with hyperglycaemia. Both hormones are known
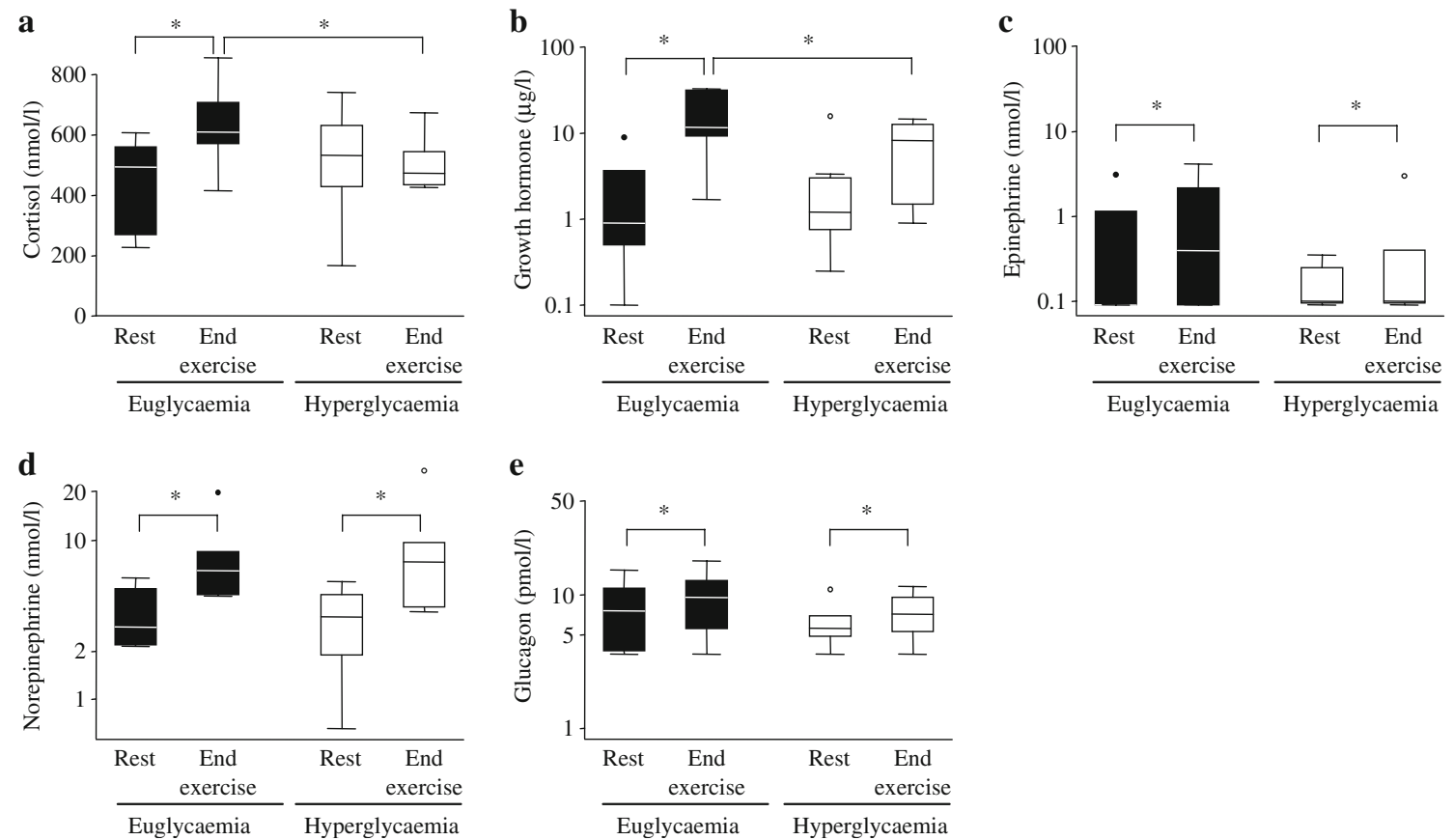

Fig. 5 Serum cortisol (a), growth hormone (b), epinephrine (c), norepinephrine (d) and plasma glucagon (e) concentrations at rest and at the end of exercise. Data are means \pm SEM, $n=7$ (a-c, e), $n=6(\mathbf{d})$; ${ }^{*} p=0.05$. Note that $\log$ scales on the $y$-axis were used in $\mathbf{b}-\mathbf{e}$ since

data were not normally distributed. Data points outside of the range of the plot are shown by black circles (euglycaemia) and white circles (hyperglycaemia) 
to induce peripheral lipolysis [33] and could have played a role in the shift towards higher lipid oxidation in euglycaemia compared with hyperglycaemia. This hypothesis is further substantiated by the tendency towards higher levels of NEFA in euglycaemia than in hyperglycaemia, reflecting an increased peripheral lipolysis.

Data on intramyocellular glycogen and lipids in general are scarce for patients with type 1 diabetes mellitus. In the present study, the pre-exercise concentration of IMCL and its consumption during exercise in euglycaemia were comparable to concentrations assessed by similar techniques in healthy athletes [31], the consumption of IMCL in hyperglycaemia being slightly lower. Interestingly, the results of the present study did not confirm our hypothesis regarding a saving of intramyocellular glycogen during hyperglycaemia compared with euglycaemia. The mechanisms by which hyperglycaemia increased glycogen consumption are not fully understood. Interestingly, the capacity of glycogen storage has been reported to be impaired in type 1 diabetes mellitus [34]. While the absolute amount of pre-exercise glycogen in hyperglycaemia in the present study was similar to levels found in healthy athletes $[31,35]$, pre-exercise glycogen concentrations were considerably lower in euglycaemia. Studies in healthy individuals have shown that net muscle glycogen utilisation is determined by muscle glycogen content before exercise [35]. It is a matter of debate whether this is a pure mass action effect initiated by the readily available fuel in the muscle cell, as was suggested by a genetically modified mouse model overaccumulating glycogen due to overexpression of glycogen synthase [36]. Other studies have suggested a cross-talk hypothesis through an upregulation of glycogen phosphorylase in the presence of higher glycogen stores [37]. Due to the pre-test standardisation procedures of the present study, including similar diet and physical activity before both tests, it is unlikely that the increased glycogen levels before exercise in hyperglycaemia were due to a systematically higher intake of carbohydrates in the days before. Conversely, it is conceivable that the hyperglycaemic clamp procedure, started just under $1 \mathrm{~h}$ before the pre-test MRS, induced a rapid synthesis of intramyocellular glycogen. The similar estimated rates of glycogen synthesis using the stable isotope data before exercise do not necessarily argue against this hypothesis, since it is unknown whether glycogen synthesis is a linear process and it is possible that synthesis was mainly activated in the early stage of the hyperglycaemic clamp. In agreement with this hypothesis, it has been shown previously that a single high-carbohydrate meal taken $4 \mathrm{~h}$ before exercise may increase glycogen content in M. vastus by over $40 \%$ [9].

The present study provides a complementary approach to the recent study of Chokkalingam and colleagues [7].
While they assessed the influence of differing insulin concentrations in euglycaemia on whole-body and muscle metabolism, the present study investigated the impact of dissimilar glucose concentrations at stable and comparably low insulinaemia on fuel metabolism during exercise. They reported an increase in exogenous glucose utilisation in hyperinsulinaemia, without concomitant sparing of muscle glycogen utilisation, which is consistent with the present results. The longer exercise duration of the present study allowed us to observe changes in aerobic substrate metabolism over an extended follow-up. In addition, insulin concentrations in the present study were lower than both insulin levels in Chokkalingam's trial in order to reflect insulin dose reductions before and during exercise as recommended by treatment guidelines [1].

The strengths of the present study are its standardised and randomised design, combining techniques to quantify glucose turnover by stable isotope tracer technique with non-invasive methods to quantify IMCL and glycogen. Glycogen measurements derived from indirect calculations were consistent with the results from MRS. We nevertheless acknowledge several limitations: First, the complex study design limited the number of participants. Second, our insight into lipid metabolism did not encompass turnover quantification using tracer technique. We agreed to this compromise in order to keep the technical interventions manageable and thereby ensure the quality of the performed measurements. Third, due to technical reasons (duration of exercise, magnetic field) no heating box could be used for the clamp. Importantly, previous studies have confirmed sufficient arterialisation of antecubital venous blood during exercise of similar duration and intensity [12]. Fourth, the maintenance of hyperglycaemia by continuous glucose infusion was an artificial intervention, limiting the direct applicability of our findings to daily clinical practice. Conversely, a deeper insight into the metabolic processes during exercise in type 1 diabetes mellitus patients under controlled conditions may still be a step towards the refinement of treatment guidelines for these patients.

In conclusion, the results of the present study suggest that substrate oxidation in type 1 diabetic patients performing aerobic exercise in euglycaemia is comparable to that observed in healthy individuals, revealing a shift towards lipid oxidation in the course of exercise. In contrast, exercising in hyperglycaemia retains fuel metabolism in an artificially restrained state of carbohydrate predominance. No evidence was found for a saving of intramyocellular glycogen in hyperglycaemia. Further studies investigating fuel metabolism during exercise in patients with type 1 diabetes mellitus should now focus on the intracellular mechanisms involved in the regulation of substrate oxidation in different glycaemic states. 
Acknowledgements This study was supported by unrestricted grants from the Oetliker-Stiftung für Physiologie (Oetliker Foundation for Physiology), from the Swiss Diabetes Foundation, from NovoNordisk, Switzerland and from the Swiss National Science Foundation (grant number $320000-109522 / 1$ to E. Christ). C. Stettler is a PROSPER fellow supported by the Swiss National Science Foundation (grant number 3233B0-115212). The MRUI software package was kindly provided by the participants of the EU Network programmes Human Capital and Mobility (CHRX-CT94-0432) and Training and Mobility of Researchers (ERB-FMRX-CT970160).

Duality of interest The authors declare that there is no duality of interest associated with this manuscript.

\section{References}

1. Zinman B, Ruderman N, Campaigne BN, Devlin JT, Schneider SH (2004) Physical activity/exercise and diabetes. Diabetes Care 27(Suppl 1):S58-S62

2. Horton ES (1988) Role and management of exercise in diabetes mellitus. Diabetes Care 11:201-211

3. Berger M, Berchtold P, Cuppers HJ et al (1977) Metabolic and hormonal effects of muscular exercise in juvenile type diabetics. Diabetologia 13:355-365

4. Koivisto VA, Felig P (1978) Effects of leg exercise on insulin absorption in diabetic patients. N Engl J Med 298:79-83

5. Wallberg-Henriksson H, Gunnarsson R, Rossner S, Wahren J (1986) Long-term physical training in female type 1 (insulin-dependent) diabetic patients: absence of significant effect on glycaemic control and lipoprotein levels. Diabetologia 29:53-57

6. Grimm JJ, Ybarra J, Berne C, Muchnick S, Golay A (2004) A new table for prevention of hypoglycaemia during physical activity in type 1 diabetic patients. Diabetes Metab 30:465-470

7. Chokkalingam K, Tsintzas K, Norton L, Jewell K, Macdonald IA, Mansell PI (2007) Exercise under hyperinsulinaemic conditions increases whole-body glucose disposal without affecting muscle glycogen utilisation in type 1 diabetes. Diabetologia 50:414-421

8. Stettler C, Jenni S, Allemann S et al (2006) Exercise capacity in subjects with type 1 diabetes mellitus in eu- and hyperglycaemia. Diabetes Metab Res Rev 22:300-306

9. Coyle EF, Coggan AR, Hemmert MK, Lowe RC, Walters TJ (1985) Substrate usage during prolonged exercise following a preexercise meal. J Appl Physiol 59:429-433

10. Coyle EF, Hamilton MT, Alonso JG, Montain SJ, Ivy JL (1991) Carbohydrate metabolism during intense exercise when hyperglycemic. J Appl Physiol 70:834-840

11. Jeukendrup AE, Raben A, Gijsen A et al (1999) Glucose kinetics during prolonged exercise in highly trained human subjects: effect of glucose ingestion. J Physiol 515:579-589

12. Hawley JA, Bosch AN, Weltan SM, Dennis SC, Noakes TD (1994) Glucose kinetics during prolonged exercise in euglycaemic and hyperglycaemic subjects. Pflugers Arch 426:378-386

13. Carter JM, Jeukendrup AE, Mann CH, Jones DA (2004) The effect of glucose infusion on glucose kinetics during a 1-h time trial. Med Sci Sports Exerc 36:1543-1550

14. Manzon A, Fisher SJ, Morais JA et al (1998) Glucose infusion partially attenuates glucose production and increases uptake during intense exercise. J Appl Physiol 85:511-524

15. Yaspelkis BB 3rd, Patterson JG, Anderla PA, Ding Z, Ivy JL (1993) Carbohydrate supplementation spares muscle glycogen during variable-intensity exercise. J Appl Physiol 75:14771485
16. Coyle EF, Coggan AR, Hemmert MK, Ivy JL (1986) Muscle glycogen utilization during prolonged strenuous exercise when fed carbohydrate. J Appl Physiol 61:165-172

17. Harger-Domitrovich SG, McClaughry AE, Gaskill SE, Ruby BC (2007) Exogenous carbohydrate spares muscle glycogen in men and women during $10 \mathrm{~h}$ of exercise. Med Sci Sports Exerc 39:2171-2179

18. Stellingwerff T, Boon H, Gijsen AP, Stegen JH, Kuipers H, van Loon LJ (2007) Carbohydrate supplementation during prolonged cycling exercise spares muscle glycogen but does not affect intramyocellular lipid use. Pflugers Arch 454:635-647

19. Tounian P, Schneiter P, Henry S, Tappy L (1996) Effects of infused glucose on glycogen metabolism in healthy humans. Clin Physiol 16:403-416

20. Hargreaves M, Briggs CA (1988) Effect of carbohydrate ingestion on exercise metabolism. J Appl Physiol 65:1553-1555

21. Borg G (1970) Perceived exertion as an indicator of somatic stress. Scand J Rehabil Med 2:92-98

22. Maroni BJ, Steinman TI, Mitch WE (1985) A method for estimating nitrogen intake of patients with chronic renal failure. Kidney Int 27:58-65

23. Frayn KN (1983) Calculation of substrate oxidation rates in vivo from gaseous exchange. J Appl Physiol 55:628-634

24. Ferrannini E (1988) The theoretical bases of indirect calorimetry: a review. Metabolism 37:287-301

25. DeFronzo RA, Tobin JD, Andres R (1979) Glucose clamp technique: a method for quantifying insulin secretion and resistance. Am J Physiol 237:E214-E223

26. Wolfe RR, Chinkes DL (2005) Isotope tracers in metabolic research: principles and practice of kinetic analysis, 2nd edn. Wiley-Liss, Hoboken

27. Robert JJ, Koziet J, Chauvet D, Darmaun D, Desjeux JF, Young VR (1987) Use of 13C-labeled glucose for estimating glucose oxidation: some design considerations. J Appl Physiol 63:1725-1732

28. Shulman GI, Rothman DL, Chung Y et al (1988) 13C NMR studies of glycogen turnover in the perfused rat liver. J Biol Chem 263:50275029

29. Boesch C, Slotboom J, Hoppeler H, Kreis R (1997) In vivo determination of intra-myocellular lipids in human muscle by means of localized 1H-MR-spectroscopy. Magn Reson Med 37:484-493

30. Boesch C, Decombaz J, Slotboom J, Kreis R (1999) Observation of intramyocellular lipids by means of $1 \mathrm{H}$ magnetic resonance spectroscopy. Proc Nutr Soc 58:841-850

31. Zehnder M, Christ ER, Ith M et al (2006) Intramyocellular lipid stores increase markedly in athletes after 1.5 days lipid supplementation and are utilized during exercise in proportion to their content. Eur J Appl Physiol 98:341-354

32. Marliss EB, Vranic M (2002) Intense exercise has unique effects on both insulin release and its roles in glucoregulation: implications for diabetes. Diabetes 51(Suppl 1):S271-S283

33. Moller N, Jorgensen JO, Alberti KG, Flyvbjerg A, Schmitz O (1990) Short-term effects of growth hormone on fuel oxidation and regional substrate metabolism in normal man. J Clin Endocrinol Metab 70:1179-1186

34. Bak JF, Jacobsen UK, Jorgensen FS, Pedersen O (1989) Insulin receptor function and glycogen synthase activity in skeletal muscle biopsies from patients with insulin-dependent diabetes mellitus: effects of physical training. J Clin Endocrinol Metab 69:158-164

35. Weltan SM, Bosch AN, Dennis SC, Noakes TD (1998) Preexercise muscle glycogen content affects metabolism during exercise despite maintenance of hyperglycemia. Am J Physiol 274:E83-E88

36. Pederson BA, Cope CR, Irimia JM et al (2005) Mice with elevated muscle glycogen stores do not have improved exercise performance. Biochem Biophys Res Commun 331:491-496

37. Laurent D, Hundal RS, Dresner A et al (2000) Mechanism of muscle glycogen autoregulation in humans. Am J Physiol Endocrinol Metab 278:E663-E668 